\title{
Um "skyline" em mutação: o velho centro e as transformações urbanas em Belém
}

\section{A "skyline" in changing: the old center and the urban transformations in Belém}

Saint-Clair Cordeiro da Trindade Júnior - Doutor em Geografia Humana pela USP. Professor do Núcleo de Altos Estudos Amazônicos da Universidade Federal do Pará (NAEA/ UFPA), pesquisador do Conselho Nacional de Desenvolvimento Científico e Tecnológico (CNPq).E-mail: stclair@ufpa.br

\section{Resumo}

Os processos de requalificação de áreas centrais nas cidades brasileiras têm colocado questionamentos sobre a natureza da apropriação do espaço que se faz presente nessas cidades. Nesse sentido, busca-se indagar se as mudanças observadas na realidade urbana do Brasil seriam semelhantes às repercussões socioespaciais verificadas em outros países que vivenciaram processos de gentrificação. Ao discutir o caso de Belém, a análise situa a importância das intervenções urbanísticas no centro histórico da cidade e estabelece relação com o perfil das transformações que acontecem nos bairros de seu entorno imediato. Conclui-se mostrando que o centro histórico, pontualmente renovado, juntamente com alguns espaços que lhe são adjacentes, vivenciam processos de apropriação que sugerem pensar em uma forma embrionária de gentrificação urbana, mas com contornos particulares, e que merece ser adjetivada.

\section{Palavras-chave}

Reestruturação Urbana. Área Central. Requalificação Urbana. Apropriação do Espaço. Gentrificação. Belém.

\begin{abstract}
The requalification of central areas in the Brazilian cities have posed questions about the nature of the appropriation of the space that is present in some cities. In this sense, the article asks if the changes observed in the Brazil urban reality would be similar to the socio-spatial repercussions verified in other countries that experienced gentrification processes. In discussing the case of Belém, the analysis situates the importance of urban interventions in the center of this city and establishes a relation with the profile of the transformations that take place in its immediate neighborhoods. In conclusion, it shows that the historical center, punctually renewed, along with some adjacent spaces, experience processes of appropriation that suggest to think about an initial form of urban gentrification, but with particular contours, that needs to be qualified.
\end{abstract}

\section{Keywords}

Urban Restructuring. Downtown. Urban Renewal. Space Appropriation. Gentrification. Belém. 


\section{INTRODUÇÃO}

A partir do encontro do rio Guamá com a baía de Guajará, um skyline $e^{1}$ muito característico nos leva de imediato ao reconhecimento desta que é uma das cidades mais expressivas do cenário urbano brasileiro. Sempre a partir dos rios, consegue-se identificar, em primeiro plano, o mercado do Ver-o-Peso, com suas feiras, portos e embarcações, ladeados pelo casario antigo, pelo Forte que lhe deu origem e pelas igrejas barrocas com suas imponentes torres. Ao fundo, um movimento de arranha-céus se soma à composição daquela que se tornou conhecida, desde os primeiros momentos de sua história, como Santa Maria de Belém do Grão-Pará.

Num esforço similar ao empreendido pela arqueologia, poderíamos proceder à leitura da silhueta dessa cidade num reconhecimento de camadas ou estratos históricos capazes de revelar não apenas linhas arquitetônicas que lhes são características, como também estéticas e conteúdos socioeconômicos, simbólico-cultural e artístico-arquitetônicas que se mostram ao observador por meio de perfis espaço-temporais de diferentes períodos de sua trajetória.

A "Belém portuguesa" a nós se apresenta como o primeiro desses estratos, por meio, por exemplo, do Forte e do casario colonial, que identificam, com seus traços e desenhos, a cidade em sua gênese, tornada o ponto de partida para a conquista do vale amazônico pelos colonizadores a partir do século XVII. A "Belém italiana" se revela em seguida, como segundo estrato, em forma de igrejas barrocas, de palácios e de espaços públicos surgidos no século XVIII por meio, por exemplo, dos rabiscos caprichosos do urbanismo bolonhês de Antônio Landi $^{2}$. Referem-se esses dois estratos a uma Belém mais antiga, sem ainda os grandes traços de modernidade que lhe seriam acrescentados a partir da segunda metade do século XIX.

Sucedendo aquelas camadas, portanto, é que nos deparamos com a estética de uma pretensa "Paris N'América", em forma de mercados, de portos, de boulevares, de mobiliários urbanos e de elementos outros que são tradução

\footnotetext{
Essa palavra, de origem inglesa - sky (céu, horizonte) e line (linha, traço) - compõe o glossário da Arquitetura, do Urbanismo, do Planejamento e da Geografia Urbana, referindo-se à silhueta arquitetônica de uma cidade que se projeta no horizonte, tendo o céu como fundo. Ela demarca, em forma de desenho, os contornos e elementos que são mais característicos de uma cidade e que chamam a atenção quando vista a partir de uma certa distância, tornando-a facilmente reconhecida por meio de suas linhas, símbolos, edifícios e traços, a exemplo do que acontece com os skylines de Londres, Paris, Nova Iorque e Rio de Janeiro, que são inconfundíveis em relação a outras cidades.

2 Arquiteto italiano bolonhês que, com seus desenhos, traços e estética, muito influenciou a arquitetura e a concepção urbanística da cidade a partir do século XVIII.
} 
na cidade de um padrão urbanístico francês e inglês da Belle Époque europeia. E a essa cidade de estilo sofisticado, ajusta-se, por fim, e ao fundo de toda a composição eclética mencionada, uma "Belém miamizada", com edifícios de até quarenta andares, a desenhar uma espécie de paisagem pós-moderna, configuradora de bairros contíguos ao seu núcleo central, aqui também chamado de centro histórico.

Emoldurando esse ecletismo urbano, têm-se ainda a floresta e os rios, onde a presença de barcos e de canoas que, ao aportarem na cidade com pessoas e produtos procedentes do interior da região, denunciam a permanência de um tempo lento que, mesmo atual, parece anterior a tudo isso, pois é portador de valores e de culturas que têm sua origem antes mesmo que essa sucessão de camadas de tempos e de objetos espaciais tivessem ganhado configuração na forma de cidade.

É nesse cenário urbano, à maneira de um mosaico geográfico, que, há quase duas décadas, projetos e obras de intervenção começaram a sinalizar para uma tendência de requalificação urbana no centro histórico da cidade, buscando dar outra qualidade, de forma e de conteúdo, ao espaço pré-existente. A exemplo de outras cidades brasileiras, a riqueza patrimonial e outros apelos paisagísticos tornaramse os elementos centrais das propostas de requalificação em curso, redefinindo parcialmente usos e formas de apropriação do espaço de sua área central.

Das repercussões geradas pelas mudanças, surgem questionamentos se centros históricos em mutação no Brasil, como o de Belém, seguiriam os mesmos destinos daqueles outros de cidades europeias e norte-americanas, que vivenciaram ou estariam vivenciando o difundido processo de gentrificação urbana $^{3}$. A presente reflexão busca discutir essa questão. Além de situar a importância das intervenções urbanas nas áreas mais centrais de Belém, associa o perfil que apresentam às repercussões imediatas no contexto da reestruturação urbana que se anuncia, especialmente nos chamados bairros pericentrais, e, ao mesmo tempo, busca indagar se, nesse caso, poder-se-ia falar também de tendência de gentrificação do seu centro histórico.

Nessa mesma perspectiva, chama-se atenção, em particular, para especificidades do processo em curso, que visa a inserção de Belém na lógica

Com apoio nas contribuições de Smith (2006), entende-se a gentrificação como um processo originado nos anos 1960, que ganhou generalização no urbanismo contemporâneo mundial, pressupondo ações do mercado e do Estado no espaço acompanhadas de discursos de "reabilitação" ou de "regeneração" urbana. Associadas a uma geografia econômica em plena mudança, tais ações implicam no deslocamento dos moradores das classes populares das áreas centrais para outros espaços das cidades, em razão das alterações que aquelas áreas passam a vivenciar em sua paisagem cultural e em seu conteúdo social. 
competitiva das cidades contemporâneas, assim como, para novas formas de apropriação material e simbólica, por parte dos agentes locais, em relação aos espaços renovados, que configuram a nova paisagem urbana e que contribuem para definir práticas espaciais apoiadas em interesses e valores que acompanham os processos de transformação da cidade.

\section{REINVENTANDO O VELHO CENTRO}

Combinando rugosidades (SANTOS, 1986) ${ }^{4}$ integradas na paisagem ao longo de seus mais de quatrocentos anos de história, o skyline atual de Belém anteriormente descrito, apresenta-se para nós como um verdadeiro mosaico de tempos e espaços que narram seu passado e, igualmente, permitem compreender em muito o seu ritmo presente. Em grande parte, a imagem que se tem hoje da cidade, e mesmo da metrópole vista em seu conjunto, ganhou contornos muito fortes a partir da dinâmica imprimida pela economia da borracha na Amazônia.

É desse momento, inclusive, que o elemento mais característico de sua imagem, o mercado de ferro do Ver-o-Peso, passa a integrar a cena urbana, ainda que o entreposto comercial que lhe deu origem acompanhe praticamente toda a existência da cidade. Com a borracha, o centro histórico - com seus elementos característicos herdados de momentos anteriores, como o Forte do Presépio, e suas igrejas barrocas (das Mercês, da Sé e de Santo Alexandre), do século XVIII, no formato que possuem hoje - foi artisticamente retocado com elementos do Art Nonveau e do Art Déco e, especialmente, da arquitetura de ferro, que ajudaram a difundir a higienização da elitista Belém da borracha.

Assim, até a primeira metade do século XX, a principal imagem da cidade divulgada mundo afora era formada por esses contornos, permanecendo dessa maneira até o fim da primeira metade do século XX, quando começaram a subir os modernos edifícios comerciais e residenciais relativamente altos, encravados no interior do núcleo central e em suas imediações, alterando a paisagem que existia bem ao fundo do famoso Mercado.

Eles foram aí construídos quando a legislação urbana era permissiva com relação a esse tipo de edificação relativamente alta para os padrões construtivos

\footnotetext{
4 Termo inspirado nos estudos de Geomorfologia e que, na Geografia Humana, conforme proposição de Santos (1986), serve para referenciar formas espaciais herdadas do passado, apresentando-se, no presente, como testemunhos de dinâmicas e processos históricos mediatos que deixaram suas marcas no espaço por meio de objetos e formas que permaneceram na paisagem geográfica atual.
} 
do entorno. Essa nova paisagem permaneceu assim quase inalterada - salvo novos contornos proporcionados por um ou outro arranha-céu que a ela se somaram - até o século XXI, quando o núcleo central tem sua imagem mais uma vez alterada, com a subida das torres de altíssimo gabarito a que nos referimos anteriormente e que aparecem ao longe, bem ao fundo, a completar o skyline urbano que se desenha hoje para a cidade.

É nesse contexto que os projetos de intervenção com vistas à requalificação do núcleo central precisam ser compreendidos. Nas concepções que portam, à maneira aparente de uma "bricolagem" local/regional, reproduzem, em suas relativas sofisticações e propostas, tendências que fazem parte de ideias que circulam pelo mundo todo, difundindo e propagando modos urbanos de vida em sintonia com o processo de mundialização da cultura.

Os novos projetos urbanísticos sugerem a reinvenção da antiga cidade e de seu velho centro, sinônimo, ao olhar do poder público, de deterioração e de decadência. No lugar dele, propõe-se outro, junto com o (re)nascimento de uma cidade mais promissora e atrativa, conforme se percebe nos quatro principais projetos que se situam no interior do núcleo central ou no seu entorno imediato, e que compõem o centro histórico, a saber: o "São José Liberto", o "Feliz Lusitânia", o "Mangal das Garças" e o "Estação das Docas".

As retóricas que se associam a esses projetos trazem a preocupação de substituir uma imagem deteriorada e decadente da cidade, e especialmente de seu centro histórico, libertando-a de um passado que a torna estigmatizada e que a associava ao antigo, ao medo, ao perigo e à sua degradação física e social. Propõese, em seu lugar, espaços mais atrativos e convidativos, conforme se verifica no projeto "São José Liberto".

5 Termo originário de bricolage, da língua francesa, que se refere à prática de realizar por si próprio, em espécie de hobby, atividades manuais, normalmente domésticas, de maneira não especializada, artesanal e lúdica, com resultados ecléticos e soluções criativas, a combinar materiais, tendências e estilos diferenciados.

6 Edificação que já fora convento, olaria, hospital e, por último, cadeia pública, hoje desativada e transformada em polo joalheiro e em centro turístico e cultural.

7 Acervo formado pelo Forte do Castelo (símbolo da fundação da cidade) e por um conjunto arquitetônico adjacente, que foram requalificados e refuncionalizados para fins turísticos e culturais.

8 Grande vazio urbano na área central transformado em parque à beira-rio com elementos da flora e da fauna amazônica combinados com outros que remetem ao patrimônio arquitetônico e cultural da cidade.

9 Antigos galpões da área portuária, frutos da época áurea da borracha, transformados em um espaço waterfront, voltado para o turismo e o lazer. 
Outras vezes, a tônica da requalificação passa a ser a projeção do patrimônio histórico-cultural e o resgate de seu passado, no sentido de preservá-lo e de potenciá-lo no presente. A partir das rugosidades existentes, busca-se conferir novo sentido ao lugar e ao antigo centro, que, apresentado como esvaziado, tornase "repaginado", preenchido em suas formas e objetos, e, também, ressignificado, seja em relação às suas antigas funções, seja em relação aos novos papéis que lhes são atribuídos. Esse preenchimento do suposto vazio se faz a despeito da vida plena e das funções econômicas e socioculturais que animam o antigo centro, mas que pouco são inseridas e articuladas às novas composições espaciais propostas pelas intervenções, tal como aconteceu no projeto "Feliz Lusitânia".

Mas não é apenas o patrimônio histórico-arquitetônico que se busca projetar nessas intervenções. Nelas se faz presente, igualmente, o potencial da natureza amazônica, assimilado por meio do paisagismo que compõe a beleza cênica de alguns desses projetos, como o "Mangal das Garças". Neste caso, além do patrimônio histórico, recorre-se à beleza do rio, da fauna e da flora regional, como pretexto para pensar o centro histórico por meio de uma espécie de retórica ambiental a integrar a ideia da renovação urbana. Essa é a proposta do referido parque naturalístico, surgido em plena área central em espaço tido como ocioso e subaproveitado.

Por fim, como síntese de todas esses atributos mencionados anteriormente e presentes nas propostas de requalificação, têm-se projetos que parecem combinar todos eles - a imagem de superação do declínio e da decadência da área central; a valorização e a preservação do patrimônio histórico, cultural e arquitetônico; o potencial e a beleza cênica da natureza; e a condição de cartão postal waterfront -, a exemplo do que se observa no "Estação das Docas". Em verdade, ele é o primeiro a ser implantado entre todos os projetos, antecipando, assim, um pouco dos demais atributos que estariam presentes parcialmente naqueles outros.

Conforme já destacamos, os projetos de requalificação urbana em referência estão situados basicamente em dois bairros do centro histórico, a Cidade Velha e a Campina, ou em bairro do seu entorno imediato (o Jurunas), respectivamente os de número 7, 8 e 1 do Mapa 1. Contíguos ou às suas proximidades, têm-se os bairros tidos como de maior poder aquisitivo de Belém, nomeadamente, Batista Campos, Nazaré, Reduto e Umarizal, respectivamente reconhecidos por meio dos números 14, 13, 9 e 10 do mapa anteriormente mencionado. 
Mapa 1 - Belém: bairros oficiais

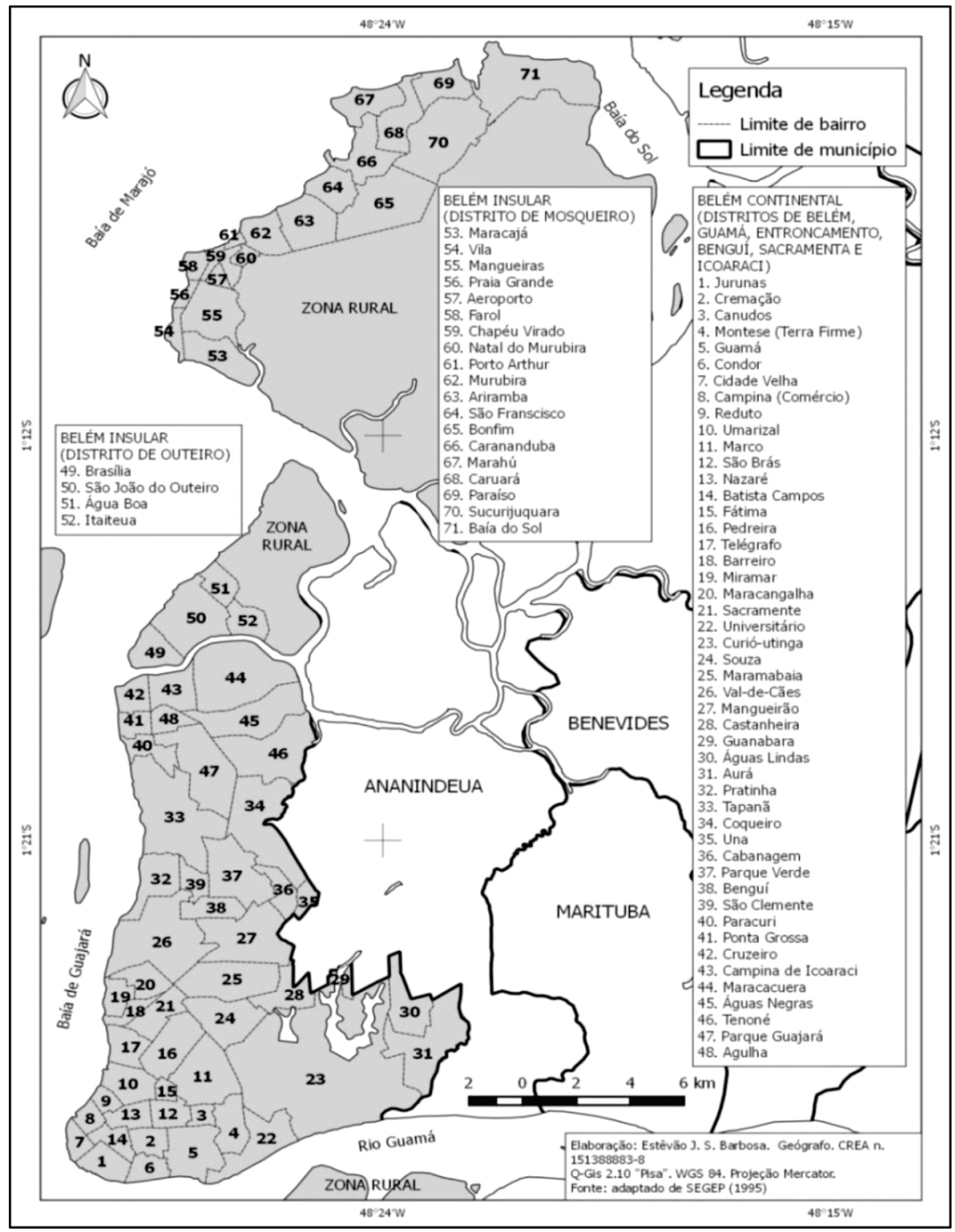

Nesses bairros, novos produtos imobiliários são ofertados, apelando ao massificado hábito de consumo de uma classe média em ascensão e que se faz refletida na paisagem por meio de arranha-céus. É principalmente a essas classes sociais, localizadas em bairros como os do entorno do centro histórico, que os projetos de requalificação urbana, colocados em prática a partir do início do século XXI em Belém, parecem, em boa parte, atender, justificando a reinvenção 
do centro para acolher novas funções associadas às velhas centralidades existentes. Compreender o sentido que é atribuído a esses espaços pressupõe entender também a estrutura urbana que lhes abriga.

\section{AMPLIANDO ESCALAS PARA ENTENDER O VELHO CENTRO}

O primeiro momento da metropolização de Belém foi responsável pela concentração de um grande contingente populacional de baixo poder aquisitivo, em parte, fruto de movimentos migratórios que reconfiguraram a forma urbana, densificando suas áreas mais centrais. Referimo-nos, particularmente, aos espaços sem infraestrutura e de péssima qualidade ambiental, abaixo da cota quatro de altimetria, chamados localmente de baixadas, e muito próximos do núcleo central da cidade (TRINDADE JR., 2016).

Diante desse processo, o velho centro, formado principalmente pelos bairros da Cidade Velha e Campina, e que antes, especialmente no auge da borracha era o espaço de circulação das elites locais, passou a se caracterizar, sobretudo a partir da segunda metade do século XX, pela forte presença do comércio popular e pelas demais práticas cotidianas associadas ao circuito inferior da economia urbana (SANTOS, 1979), do qual o complexo do Ver-oPeso é seu melhor exemplo.

Acompanhava essa mesma dinâmica, que se desenhou a partir da década de 1960 (TRINDADE JR., 2016), um processo de mudança no entorno imediato do núcleo central e que levou, nas décadas seguintes, ao processo de verticalização embrionário no seu interior e nas suas proximidades. Algumas das transformações nesse entorno imediato do núcleo central foram acompanhadas de processos de remoção de populações de baixo poder aquisitivo que habitavam moradias precárias localizadas em espaços com problemas de saneamento e infraestrutura urbana, conforme pudemos demonstrar em outro estudo sobre o processo de valorização de uma dessas áreas (TRINDADE JR., 1997).

Essa forma de reapropriação das áreas centrais foi responsável por configurar junto com outros bairros, mais bem dotados de infraestrutura, a presença de espaços pericentrais direcionados notadamente para uma demanda solvável da população local e constituindo uma espécie de cinturão de bairros verticalizados a contornar o centro histórico de Belém, que se tornou foco de intervenções pontuais, principalmente a partir do início do século XXI, sob a justificativa de requalificá-lo.

Tais intervenções vieram se somar àquelas estratégias do mercado imobiliário no entorno desse mesmo centro histórico, que se dirigiam à produção 
de apartamentos para a classe média e alta com o apoio no sistema financeiroimobiliário. Qualquer levantamento que se faça nos bairros onde acontecem essas intervenções e que definem os novos fluxos de consumidores rumo ao centro histórico, dificilmente seria capaz de constatar aumento significativo dos valores dos imóveis nele existentes, ou mudança de perfil dos moradores, a exemplo do que acontece em cidades de países centrais que vivenciaram processos de gentrificação urbana.

Seja no bairro da Cidade Velha, seja no bairro da Campina, os principais que definem o centro histórico da cidade, poucas evidências surgem de chegada de novos moradores de mais alto poder aquisitivo, bem diferente do que se percebe nos bairros do entorno, que aqui estamos chamando de bairros pericentrais, especialmente os bairros de Batista Campos, Nazaré, Reduto e Umarizal (Mapa 1).

Os dois primeiros se caracterizam historicamente por serem os bairros que, ao longo do tempo, definiram-se, pela infraestrutura instalada e pela proximidade do núcleo central, como os de maior interesse de moradia das classes altas e médias de Belém. Os dois últimos, banhados pela baía de Guajará, situam-se, em boa parte, em antigas áreas de baixada e, até a primeira metade do século XX, eram caracterizados como bairros onde vivia uma população pobre e, no caso do Reduto, uma população operária, que trabalhava nas indústrias lá existentes até esse período.

Nesses bairros se faziam presentes, inclusive, áreas de favela, como a existente ao lado do atual Canal da Doca de Souza Franco, hoje ladeado por ampla avenida marginal ao antigo igarapé e que define o limite entre os dois bairros. Com as obras de saneamento que deram lugar a ela, os moradores pobres foram em grande parte desalojados e removidos para a área de expansão na periferia distante de Belém, ainda na década de 1960. No espaço de onde foi tirada a população, bem como em seus arredores, promoveu-se a chegada de uma nova classe média, incentivada a morar em apartamentos às proximidades do núcleo central, dos principais serviços, em área saneada e infraestruturada, conforme pudemos demonstrar em trabalho anterior (TRINDADE JR., 1997).

No caso do Umarizal, trata-se, na verdade, de um bairro pericentral a abrigar principalmente camadas altas e médias da população belenense que apreciam a vista da baía e os serviços culturais e de entretenimento que a proximidade do centro proporciona, mas principalmente os valores de uma nova classe média que é atraída pela presença de espaços de lazer, de contemplação, de serviços, de consumo em geral, considerados seletos.

Em outro extremo do pequeno semicírculo dos bairros pericentrais, às margens do rio Guamá, e acompanhando uma dinâmica embrionária semelhante 
ao do Umarizal, mesmo que retardatária em relação a este, tem-se o popular bairro do Jurunas. Esse bairro, ainda hoje é habitado majoritariamente por uma população de baixo poder aquisitivo que desfruta da proximidade do núcleo central da cidade e do rio Guamá, por onde chega parte da cultura ribeirinha que nele se reproduz. Nos últimos anos, entretanto, um processo de substituição contínuo e gradativo tem-se feito notar em setores desse bairro situados nas proximidades do núcleo central ou em seu limite com o bairro de Batista Campos.

Tal tendência mostra que o mesmo processo que se verificou no Umarizal começa também a se manifestar no Jurunas, tal a presença de investimentos imobiliários direcionados para uma classe média que ainda valoriza a proximidade do núcleo central da cidade e a proximidade de bairros tidos tradicionalmente como sendo habitados pela classe alta e média de Belém. É nesse sentido que, se quisermos entender a repercussão do processo de requalificação urbana que aconteceu no núcleo central de Belém, é necessário ampliar o campo de observação para os bairros adjacentes, aqui chamados de pericentrais.

Esses bairros, dos quais o melhor exemplo é sem dúvida alguma o Umarizal, vivem uma espécie de "boom" imobiliário que dá sentido aos novos espaços de frequência requalificados para a classe média e alta e que estão situados no interior do centro histórico, sendo por essas mesmas classes visitados de forma pontual para fins culturais e de lazer.

\section{ADJETIVANDO A GENTRIFICAÇÃO URBANA EM BELÉM}

No sentido de melhor entender o processo que aqui queremos caracterizar, tomaremos como referência estudos realizados recentemente sobre a produção imobiliária em Belém, cujos resultados e dados apresentados ratificam o argumento aqui sustentado a respeito no novo sentido atribuído ao centro histórico de Belém e da dinâmica imobiliária dos bairros de seu entorno.

Cardoso (2017), em análise sobre o mercado imobiliário e a verticalização de empreendimentos residenciais no contexto belenense, demonstra a lógica e as estratégias do processo de apropriação do espaço nas proximidades do núcleo central, em cotejo com os demais espaços de expansão imobiliária. Seu estudo se voltou para onze bairros onde se pode detectar, por meio de dados quantitativos, a maior incidência da corrida imobiliária, responsável, em consequência, pelo incremento da produção vertical na cidade.

Com uma amostra de 1.720 anúncios levantados em empresa on line de compra e venda e de locação de produtos imobiliários ${ }^{10}$, analisa indicadores

${ }_{10} \quad$ Base de dados elaborada a partir do site da empresa OLX. 
desse mercado na cidade. Tais indicadores levam à constatação, como já era de se esperar, que a zona central de Belém - onde se encontram os bairros centrais e pericentrais, como Batista Campos, Nazaré, Umarizal e Reduto - é a que detém os mais altos valores de mercado.

Considerando os valores médio do preço de aluguel em 2016, tem-se, em ordem decrescente, as seguintes performances dos onze bairros considerados: 1) Batista Campos (R $\$ 2.484,75), 2)$ Umarizal ( $\$ 2.346,26), 3)$ Nazaré (R $\$ 2.310,34)$, 4) Reduto ( $\mathrm{R} \$ 2.025,43)$, 5) São Brás $(\mathrm{R} \$ 1.833,62)$, 6) Marco $(\mathrm{R} \$ 1.747,93), 7)$ Parque Verde (R\$1.694,77), 8) Pedreira (R\$1.545,86), 9) Souza (R\$1.224,04), 10) Coqueiro ( $\mathrm{R} \$ 1.035,45), 11)$ Marambaia ( $\$$ 892,81) (CARDOSO, 2017).

Tomando como parâmetro os valores médios do preço de venda por bairro, os resultados foram os seguintes: 1) Umarizal ( $\$$ \$63.064,14), 2), Nazaré (R\$750.000,00), 3) Souza (R\$659.642,86), 4) Reduto (R\$653.100,00), 5) Batista Campos ( $\mathrm{R} \$ 550.432,28)$, 6) Marco $(\mathrm{R} \$ 454.583,33), 7)$ Pedreira ( $\$ 337.626,60)$, 8) São Brás $\mathrm{R} \$ 345.785,71)$, 9) Parque Verde (R $\$ 299.811,04), 10)$ Marambaia (R\$198.026,81), 11) Coqueiro (R \$146.772,27) (CARDOSO, 2017).

Nesse estudo, o autor constata ser o Umarizal, dentre os bairros da área mais central de Belém, o principal alvo da verticalização e a atrair a atenção das principais empresas que atuam na produção imobiliária da cidade nos últimos anos, chegando essas mesmas empresas a somarem juntas aproximadamente $70 \%$ dos investimentos imobiliários existentes no bairro, percentual esse assim distribuído: Quadra Engenharia (13,3\%), Marko Engenharia (11,7\%), Síntese Engenharia (11,7\%), Cyrela Brazil (8,3\%), Reality (8,3\%), Freire Mello (8,3\%) e Leal Moreira (8,3\%) (CARDOSO, 2017).

A mesma importância do bairro do Umarizal aparece na análise de Ventura Neto (2015). Segundo esse autor, nos últimos anos, coalizões de interesses das empresas imobiliárias ajudaram a promover a reestruturação urbana em Belém, que tem reforçada a sua estrutura expandida de metrópole, ao mesmo tempo em que reafirma a reapropriação do espaço em bairros situados no entorno do centro histórico.

Esta última tendência pode ser percebida por meio da performance dos bairros que possuem o maior número de novos empreendimentos imobiliários por bairros no período de 1999 a 2011 (Tabela 1); dados esses informados pelo autor a partir de dados da Secretaria de Urbanismo (SEURB) sistematizados pelo Núcleo Belém do Observatório das Metrópoles para o período de 1999 a 2008, e pelo próprio autor, para o período de 2009 a 2011 (VENTURA NETO, 2015). 
Tabela 1 - Belém: bairros com maior número de novos empreendimentos (1999-2011)

\begin{tabular}{c|l|c|r}
\hline Posição & Bairro & Número de novos empreendimentos & \% do total \\
\hline 1 & Umarizal & 40 & $22,73 \%$ \\
\hline 2 & Marco & 29 & $16,48 \%$ \\
\hline 3 & Pedreira & 21 & $11,93 \%$ \\
\hline 4 & Batista Campos & 16 & $9,09 \%$ \\
\hline 5 & Nazaré & 16 & $9,09 \%$ \\
\hline 6 & Jurunas & 11 & $6,25 \%$ \\
\hline
\end{tabular}

Fonte: SEURB. Elaboração: Núcleo Belém/Observatório das Metrópoles para o período de 1999 a 2008 (2008); próprio autor para o período de 2009 a 2011 (2012) apud Ventura Neto (2015, p. 137).

Do estudo realizado por Ventura Neto (2015), buscamos listar apenas os bairros com melhores performances em relação ao número de novos empreendimentos. Nessa lista, além dos principais bairros pericentrais já mencionados, dois outros - Marco e Pedreira (respectivamente 11 e 16 no Mapa 1) - indicam os vetores de expansão dos investimentos imobiliários mais próximos do núcleo central. Entre os seis bairros que encabeçam a lista, o de maior destaque é novamente o Umarizal.

Essa tendência de verticalização do bairro é facilmente percebida na paisagem da cidade há alguns anos, conforme mencionado em estudo que fizemos ainda no início da década de 1990 (TRINDADE JR., 1997); momento em que citamos matéria do jornalista e sociólogo Lúcio Flávio Pinto, que já alertava para esse processo de valorização do Umarizal no final dos anos 1970:

na memória dos belenenses ainda estava muito viva a lembrança do que aconteceu com os moradores da baixada da Marechal Hermes e de todo o canal do igarapé das Almas. Ontem este mesmo jornal informava que a Prefeitura autorizou a construção de mais 18 prédios residenciais na doca de Souza Franco, que se juntarão aos sete em construção. Brevemente todo o cenário dessa área terá sido mudado: um visitante não imaginará que ali existia uma baixada idêntica à do Una (PINTO, 1979, p. 6 apud TRINDADE JR., 1997, p. 148).

Observações semelhantes do mesmo autor são citadas em recente estudo sobre a verticalização em Belém realizado por Vieira (2017), demonstrando o quanto o crescimento vertical do bairro é facilmente detectado no conjunto da cidade. 
uma única construtora está levantando, ao mesmo tempo, sete novos prédios no bairro do Umarizal, a maioria com mais de 30 andares. Se essa febre continuar, os moradores de Belém vão pagar a conta do calor: o paredão de concreto que está se formando no antes aprazível e ventilado Umarizal vai afetar toda a cidade. Não está mais exatamente na hora de regulamentar a onda de espigões nessa área, tão intensamente explorada pela construção civil e seu vício acompanhante, a especulação imobiliária. Já está tarde (PINTO, 2003, p. 6 apud VIEIRA, 2017, p. 125-126).

Não só se multiplicaram com grande rapidez os prédios como eles foram se tornando cada vez mais altos. Já são numerosos os "arranha-céus" com mais de 30 andares e agora a cidade já tem um novo topo: as duas torres de 40 andares levantadas na valorizada Doca de Souza Franco, que acabaram com o reinado de meio século do "Manuel Pinto da Silva" como o edifício mais alto do Norte e Nordeste do Brasil.

A desenfreada verticalização ocorre exatamente quando a frota de veículos também experimenta desempenho semelhante, batendo em quase 300 mil veículos, sem que o poder público tenha acompanhado as duas evoluções. Parece que Belém toma São Paulo como modelo (PINTO, 2012, p. 7 apud VIEIRA, 2017, p. 126).

O que se percebe por meio da simples observação da paisagem pode ser também ratificado por meio de dados que demonstram o avanço da produção imobiliária no bairro, conforme ainda a sistematização de Vieira (2017), ao mostrar que até o ano de 2005 o bairro possuía apenas 90 edifícios verticais. Essa situação mudou ao longo dos anos, passando a 130 edificações em 2009 e a 174 em 2015.

Conforme o mesmo autor, o percentual de crescimento do número de edifícios no primeiro período referenciado em sua série temporal (julho de 2005 a julho de 2009) é de 44,4\%, e de 33,8\% para o segundo período (julho de 2009 a julho de 2015), que permanece relativamente elevado se considerarmos que este último adentra nos anos de crise econômica mundial, repercutindo na desaceleração de crescimento do setor imobiliário em nível local. O fato é que em dez anos a quantidade de edifícios no bairro do Umarizal teve um crescimento de quase $100 \%$, uma vez que saltou de 90, em julho de 2005, para 174 edifícios, em julho de 2015 (VIEIRA, 2017).

O que justifica esse processo de valorização de bairros pericentrais como o Umarizal? Sem dúvida, a tendência das classes de mais alto poder aquisitivo de habitar as áreas centrais da cidade, considerando fatores tais como: o potencial e a relativa qualidade da infraestrutura instalada ao longo de sua história, a proximidade dos principais serviços voltados às classes mais solventes, os investimentos em obras de saneamento e macrodrenagem nas antigas áreas de 
baixadas por parte do Estado, as amenidades naturais e as socialmente produzidas ligadas à imagem da cidade.

Em relação a estas últimas, o fato de o Umarizal situar-se às margens da baía de Guajará tem sido um dos elementos que se fazem presentes no marketing das empresas imobiliárias responsáveis pela produção de apartamentos em prédios verticais nesse bairro. Soma-se a isso, entretanto, como hipótese, o fato de que a nova imagem que se tem veiculado a respeito da cidade, encontra-se diretamente associada aos novos espaços requalificados no interior de seu centro histórico ou mesmo em suas imediações. Não coincidentemente, o avanço imobiliário no bairro se deu concomitantemente à tentativa do poder público de definir uma nova imagem para o centro histórico da cidade e, igualmente, de voltar o olhar de seus habitantes em direção aos rios, por muito tempo negados pelo processo de crescimento urbano.

Nesse sentido, diferentemente do que acontece em grande parte das cidades de países centrais, que têm vivenciado processos clássicos de gentrificação urbana, no caso de Belém, as classes de mais alta renda não tendem a substituir as populações de inferior poder aquisitivo a elas que habitam o núcleo central; mesmo porque o processo de requalificação não tem sido extensivo àquelas edificações residenciais de valor histórico-patrimonial situados no interior do centro histórico.

A processos semelhantes como esses, autores diferentes não têm descartado o reconhecimento da gentrificação. Buscam, entretanto, adjetivá-la, de maneira a melhor caracterizar as particularidades das formas como se manifestam em distintas realidades, por se tratar, com efeito, de uma estratégia urbana de nível global, conforme pontua Smith (2006), que chama a atenção para o fato de que:

seria um erro considerar o "modelo nova-iorquino" como uma espécie de paradigma, e medir o progresso da gentrificação em outras cidades pelos estágios que foram lá identificados. Não é isso o que estou sugerindo. Por ser uma expressão de relações sociais, econômicas e políticas mais amplas, a gentrificação em uma cidade específica irá exprimir as particularidades da constituição de seu espaço urbano (SMITH, 2006, p. 74).

Buscando entender tais particularidades, autores como Van Criekingen (2006), chamam atenção para a necessidade de buscar elementos reveladores do mesmo processo em diversas realidades locais:

compreender as transformações contemporâneas dos espaços urbanos antigos, tanto para superar o entusiasmo imediato dos discursos sobre o "renascimento" do centro, como a desolação fatalista quanto a seus impactos sobre as populações pobres, exige antes de tudo quebrar o 
molde indiferenciado do "gentrificador" e da dinâmica da qual ele era o herói. A demanda por espaços urbanos revitalizados é assegurada por grupos econômicos e demográficos diversificados, com modos de inserção no mercado da habitação e itinerários residenciais variados (VAN CRIEKINGEN, 2006, p. 112).

Sustenta que as situações tendem a variar bastante, e a reapropriação residencial e comercial, mesmo a de atividades de escritório, com finalidades turísticas ou recreativas, na verdade, expressam-se em diversas combinações nos bairros antigos em transformação (VAN CRIEKINGEN, 2006, p. 97-98). Acompanhando o seu raciocínio, diríamos também que tais combinações das dinâmicas urbanas que se relacionam à gentrificação extrapolam mesmo os limites de bairros objetos de intervenção urbana.

De sua discussão sobre Bruxelas, a diferença que faz entre a "gentrificação residencial" e "gentrificação do consumo" parece interessar à interpretação de situações como a aqui apresentada a respeito de Belém. Chama a atenção, entretanto, o processo de substituição que tem ocorrido notadamente no entorno do chamado centro histórico, que parece possuir certa sintonia com o movimento pontual de requalificação no interior desse mesmo espaço.

Nesse caso, não se constata de maneira genérica a requalificação de antigas estruturas comerciais e residenciais que promovam uma mudança completa no interior do centro histórico, mas sobretudo a produção de um novo espaço e de imóveis mais modernos no entorno que, fundada no discurso da segurança e das opções de lazer que oferecem, tornam-se atrativos às classes médias e altas que não demonstram interesse em habitar o velho centro em imóveis antigos, mesmo que restaurados. Os indícios de requalificação desses antigos imóveis, se existem, são ainda muitos tímidos e se prestam principalmente a serviços e atividades comerciais muito pontuais.

No entorno da "Estação das Docas", por exemplo, chama a atenção a restauração de alguns exemplares de um conjunto de casario antigo situado a sua frente, onde foi instalado um espaço cultural, voltado a atividades do Serviço Social do Comércio (SESC), e um restaurante pouco convencional de venda de açaí, com uma proposta mais sofisticada de atendimento aos que visitam a cidade e a um público local mais seleto.

Nas imediações do complexo "Feliz Lusitânia" também somente duas novas atividades instaladas em prédios de valor histórico atraem a atenção. Tratase de restaurantes especializados em comida internacional, sendo que em um deles também funciona uma espécie de hotel de charme, que associa os serviços 
de hospedagem oferecidos à beleza e ao valor histórico do bairro da Cidade Velha e às amenidades dos espaços restaurados nas suas imediações.

Situação semelhante acontece com o Parque Naturalístico "Mangal das Garças", que pouco dinamizou atividades em seu entorno. As exceções referemse a um bar com proposta de música e cardápio diferenciado, frequentado por uma classe média que aprecia a boa música e a boa gastronomia local; assim como, a um hotel, de médio porte, que se instalou em um casarão restaurado no entorno do parque e que desfruta de suas amenidades apresentando-as como um dos atrativos para quem nele deseja se hospedar.

Por fim, o Polo Joalheiro e Cultural "São José Liberto" pouca repercussão trouxe no sentido de atrair novas atividades para o local onde se instalou. Se nos demais, as atividades instaladas a partir dos projetos de requalificação urbana reaproveitaram antigas estruturas arquitetônicas existentes, neste último caso, os poucos bares que no seu entorno foram dinamizados, não chegam propriamente a ocupar edificações consideradas de valor patrimonial de natureza histórica e arquitetônica.

Não se trata, portanto, no caso belenense, de gentrificação clássica, à maneira como foi descrita por Smith (2006) para as cidades de países centrais, em que as áreas renovadas pressupõem, além da restauração de antigas estruturas, a saída de classes de inferior status social e que tendem a ser substituídas por estratos sociais de mais alto poder aquisitivo. Isso não significa dizer, todavia, que o caráter classista do processo referenciado por aquele autor não se faça presente no caso belenense.

Leite, ao tratar das alterações na área central de Recife, mostra que a questão da gentrificação toca diretamente a "transformação dos significados de uma localidade histórica em um segmento do mercado, considerando a apropriação cultural do espaço a partir do fluxo de capitais" (LEITE, 2004, p. 20). E parece ser exatamente isso o que se verifica embrionariamente na realidade belenense.

Há um novo significado atribuído aos lugares requalificados que nega a presença de seus antigos frequentadores ou daqueles que circulam em seu entorno. Em contraponto, abrem-se nesses espaços possibilidades de apropriação cultural ou voltada ao lazer em forma de consumo induzidos a partir de interesses diretamente ligados, não apenas, mas principalmente, a comportamentos e valores de uma classe média local e aos turistas que visitam e frequentam, com certa regularidade, esses lugares.

Nesse sentido, em Belém, à semelhança de outras cidades brasileiras, a requalificação estimula novos usos dos espaços objetos de intervenção. Tal utilização dos espaços em referência é feita com certa recorrência dada a oferta 
de serviços ligados ao entretenimento, à vida cultural, ao turismo e ao lazer de determinadas classes sociais, que visitam a área central pontualmente, mas que não necessariamente estendem suas visitas às suas imediações; estas que são vistas normalmente como perigosas e mal frequentadas.

É esse mesmo caráter de frequência recorrente que faz Frúgoli Jr. (2006) adjetivar também o processo de gentrificação ao se referir a algumas experiências verificadas em cidades latino-americanas, mostrando que, diferentemente das constatações de Smith (2006) para Nova Iorque, em várias situações o papel do Estado é fundamental para a ocorrência desse processo, cuja expressão não é propriamente vinculada ao uso residencial.

Inspirado em Melé (2006) e Hiernaux (2006), sugere falar de "gentrificação de frequência e de consumo". Esse tipo de manifestação do processo se aproxima mais do que acontece na realidade belenense, onde, além dos turistas, que fazem dos espaços requalificados verdadeiras referências de conhecimento a respeito da cidade, algumas práticas rotineiras protagonizadas por classes médias e abastadas, por meio de seus hábitos e valores de consumo e pela proximidade e facilidade de acesso, definem a frequência, de forma mais seletiva, dos "espaços públicos" requalificados.

Exemplo disso são os concertos de música na capela do Espaço Cultural "São José Liberto" e na de Santo Alexandre; este integrante do "Feliz Lusitânia", onde são também realizados, com certa regularidade, casamentos da elite belenense ou de sua classe média, que podem pagar caro para a realização de eventos dessa natureza.

No Parque Naturalístico "Mangal das Garças", por seu turno, a frequência dessas mesmas classes acontece para usufruir do restaurante de alta qualidade que ali foi instalado e para reafirmar uma outra função que, cada vez mais, faz-se presente no interior desse espaço público. Trata-se da presença de famílias, casais, turmas de formaturas, aniversariantes e modelos que escolhem aquele espaço para servir de cenários para fotografias que irão compor books profissionais ou de datas e eventos importantes e/ou comemorativos.

Situação semelhante se constata em relação à "Estação das Docas", que apesar de possuir espaços culturais que servem de atrativos para esses mesmos estratos sociais, tem seu dinamismo atribuído especialmente pela frequência a bares e restaurantes de médio e alto padrão nela instalados, servindo também de espaço de contemplação e de uso cenográfico para fins semelhantes aos do "Mangal das Garças". Diante disso, são relativamente poucos os momentos em que uma apropriação mais diferenciada e diversa de classes e de grupos acontece, como o que se verifica nas festas de réveillon, quando então os espaços 
não privatizados por bares e restaurantes são mais plenamente ocupados pela população em geral que para lá se dirige para festejar a chegada de um novo ano.

A concepção preservacionista e a "maquinaria patrimonial" (JEUDY, 2005), sobre as quais se apoia a volta ao passado e à sua referência como condição de afirmação de uma imagem do presente, é também um mecanismo de reapropriação seletiva e de transformação de áreas tidas como "marginais" em complexos culturais e de lazer. Paradoxalmente, reforça também a segmentação dessas mesmas áreas centrais, tornadas cenários de disputas entre um espaço que se concebe para a visitação pública ocasional e seletiva e aquele que se presta a existência cotidiana dos que ali vivem e transitam a maior parte do tempo.

Esse modelo desigual de política urbana dá sentido ao que Vaz e Jacques (2006) identificam como "gentrificação cultural", que, no caso de Belém, por se fazer presente em espaços pontuais, em vez de tornar mais coeso o velho centro, culmina por fragmentá-lo ainda mais, dada a presença de espaços sofisticados culturalmente visitados e aqueles em que a cultura popular e espontânea passa a ser vista como marginal e indesejável.

Pode-se falar, assim, como Vaz e Jacques (2006), de uma "culturalização da cidade", que promove espaços desiguais em seu interior. Associada à espetacularização e ao incremento turístico, a funcionalização cultural que preenche espaços requalificados atende notadamente a objetivos econômicos e divide a cidade em "zonas culturais" - requalificadas com equipamentos culturais - e "zonas não culturais" - onde aqueles mesmos equipamentos se fazem ausentes.

Nos casos mencionados, as transformações que causaram pontualmente a determinadas frações do centro histórico de Belém e o sentido de enclave que possuem nos espaços onde se localizam, muitas vezes desarticulados e sem grandes interações com o entorno imediato, reafirmam a ideia de seletividade cultural mencionada. Trata-se de espaços que definiram novos fluxos pontuais para o núcleo central da cidade, dada a regularidade de frequência por parte de um público - turistas ou moradores locais -, que a eles se dirigem, mas que, de fato, não interagem com o centro histórico na sua totalidade.

Tornam-se, assim, reapropiados apenas pontualmente e temporariamente por classes locais de alto e médio status e por visitantes que, por meio de um consumo mais cultural e voltado ao entretenimento, contribuem para legitimar o forte apelo patrimonial, contemplativo e de lazer desses espaços. Isso a despeito dos fluxos cotidianos pré-existentes nessa área central, relacionados ao comércio popular, aos diversos portos onde ancoram os barcos regionais, às feiras e às outras atividades do circuito inferior da economia urbana (SANTOS, 1979), que aí se fazem fortemente presentes. 


\section{CONSIDERAÇÕES FINAIS}

A gentrificação tende a combinar requalificação dos usos de determinadas frações da cidade, intervenção no patrimônio histórico-cultural e arquitetônico, assim como melhorias na infraestrutura instalada, associada a uma releitura estética do espaço objeto de intervenção, que passa a atrair, por esse motivo, camadas sociais de mais alto status econômico em comparação àquelas que normalmente frequentam ou habitam esses mesmos espaços.

No caso belenense e de outras cidades brasileiras, a questão que se coloca é se as transformações que hoje essas cidades vivenciam em suas áreas centrais requalificadas traduziriam o mesmo processo de reapropriação de áreas centrais já identificado em outras cidades de outros países desde o século passado, ou se ganham novas configurações, conforme pontua Smith (2006), no século XXI. Fato comum nesses casos é a saída ou recuo de territorialidades de moradores das classes populares dos centros e a chegada e territorialização de classes economicamente mais solváveis que as substituem ou restringem seus espaços de uso e de vivência, sinalizando para a natureza classista do processo.

Reafirmando essa posição de Smith (2006), Bidou-Zachariasen (2006) sustenta que:

qualquer que seja a sua natureza, espontânea e marginal, ou programada e mundial, a gentrificação tem por corolário a saída das classes populares dos centros urbanos. E, embora a dimensão classista do processo haja sido sublinhada pelos primeiros trabalhos que a estudaram (cf. Glass), esta dimensão será eufemizada ou silenciada pelos discursos dos que a programam como política de "renascimento" ou "regeneração" urbana (BIDOU-ZACHARIASEN, 2006, p. 32).

Muito se tem falado a respeito da inexistência da gentrificação em realidades urbanas como as latino-americanas. No caso brasileiro, esse argumento tem aparecido principalmente porque os processos de mudanças por que passam os centros de cidades como Belém, não têm, de fato, trazido as classes médias e altas para habitarem seus centros históricos, não obstante o processo de requalificação por qual têm passado.

Em contrapartida, os novos espaços renovados não escapam a outras formas de apropriação por parte dessas mesmas classes, sinalizando para uma forma de gentrificação nada clássica que se manifesta, ainda que de modo tímido, e que pode revelar uma tendência de seletividade socioespacial, tal o grau de adesão que provoca nas classes médias, especialmente as que habitam bairros próximos do centro histórico. 
Resulta, em geral, da reinvenção de espaços cujas centralidades existentes são praticamente desconsideradas, recriando-se neles novos fluxos de visitantes e frequentadores motivados pela nova cidade projetada a partir de experiências de requalificação urbana. São intervenções fragmentárias e pontuais que, de forma metonímica, apresentam-se como o todo, sendo, entretanto, apenas uma parte do centro histórico.

Por essa razão, os espaços requalificados são frequentados apenas furtivamente e de forma pontual por classes de mais alto poder aquisitivo, pois não é do centro como um todo que se busca reapropriar, mas tão somente daqueles pedaços que foram renovados, requalificados e refuncionalizados para usos bem específicos. Ainda que estejam resguardados pelo discurso da socialização na condição de espaços públicos reinseridos na vida urbana, antes controlados por instituições ou esferas governamentais que lhe conferiam uso restrito ou mesmo privativo, a renovação da forma espacial e/ou arquitetônica faz assumirem uma identidade que os reduz a espaços apenas coletivos em detrimento do adjetivo "público" a que buscam estar associados.

Isso acontece porque se sujeitam a uma forma de apropriação ainda muito limitada a determinados estratos sociais, posto que as práticas de uso que lhes são induzidas pelo poder público ou pelas Organizações Sociais (OS) que os gerenciam tendem a inibir uma forma de apropriação de caráter mais universal, onde o sentido de copresença, de coabitação, possa ser marcado pela pluralidade, civilidade, diálogo e relação contratual de agentes diversos, como seria de se esperar de espaços públicos no sentido pleno do termo (GOMES, 2002). Há, portanto, uma natureza classista de apropriação do espaço a ser considerada.

$\mathrm{Na}$ verdade, referem-se verdadeiramente a espaços mediados pelo consumo, com apelos culturais, de turismo e de lazer, e que não favorecem esse sentido pleno de "público", já que são seletivos, algumas vezes camuflados, labirínticos, vigiados, material ou simbolicamente blindados e pouco favoráveis ao acesso e ao uso plural e diverso (AMENDOLA, 2000).

São esses novos conteúdos e valores da vida urbana em Belém que redesenham seu skyline. O centro histórico, agora pontualmente requalificado, continua a aparecer em primeiro plano, como acontecia nas antigas imagens que se tinha da cidade; mas, ao seu fundo, a compor uma nova imagem tornamse flagrantes os prédios em altura, como os existentes no adjacente bairro do Umarizal, um dos bairros da nova classe média de Belém, que recorrentemente passa a frequentar os espaços requalificados do centro histórico para fins de entretenimento cultural e de lazer de um modo geral, mas que não o constitui 
como seu espaço de moradia, preferindo habitar apartamentos modernos, com área de lazer completa, às suas adjacências; aí também substituindo populações de menor poder aquisitivo que habitavam esse mesmo bairro.

\section{REFERÊNCIAS}

AMENDOLA, G. La ciudad postmoderna: magia y miedo de la metrópolis contemporánea. Madrid: Celeste Ediciones, 2000. (Colección Intersecciones Arte y Arquitectura)

BIDOU-ZACHARIASEN, C. Introdução. In: (Org.). De volta à cidade: dos processos de gentrificação às políticas de "revitalização" dos centros urbanos. São Paulo: Annablume, 2006. p. 21-57.

CARDOSO, W. S. Mercado imobiliário e verticalização de empreendimentos residenciais na produção da segregação socioespacial em Belém. 2017. 436f. Tese (Doutorado em Desenvolvimento Sustentável do Trópico Úmido) de Núcleo de Altos Estudos Amazônicos, Universidade Federal do Pará, Belém, 2017.

FRÚGOLI JR., H. Intervention dans les espaces centraux des villes brésiliennes, le cas de São Paulo. In: RIVIERE D’ARC, H., MEMOLI, M. (Ed.). Le pari urbain en Amérique latine: vivre dans le centre des villes. Paris: Armand Colin, 2006. p. 133-147.

GOMES, P. C. C. A condição urbana. Rio de Janeiro: Bertrand Brasil, 2002.

HIERNAUX-NICOLAS, D. A reapropriação de bairros da Cidade do México pelas classes médias: em direção a uma gentrificação? In: BIDOUZACHARIASEN, C. (Org.). De volta à cidade: dos processos de gentrificação às políticas de "revitalização" dos centros urbanos. São Paulo: Annablume, 2006. p. 229-264.

JEUDY, H-P. Espelho das cidades. Rio de Janeiro: Casa das Palavras, 2005.

LEITE, R. P. Contra-usos da cidade: lugares e espaço público na experiência urbana contemporânea. Campinas-SP: Unicamp, 2004.

MELÉ, P. (Re)investir nos espaços centrais das cidades mexicanas. In: BIDOUZACHARIASEN, C. (Org.). De volta à cidade: dos processos de gentrificação às políticas de "revitalização" dos centros urbanos. São Paulo: Annablume, 2006. p. 167-195. 
SANTOS, M. Por uma geografia nova. 3. ed. São Paulo: HUCITEC, 1986.

O espaço dividido: os dois circuitos da economia urbana dos países subdesenvolvidos. Rio de Janeiro: Francisco Alves, 1979.

SMITH, N. A gentrificação generalizada: de uma anomalia local à "regeneração" urbana como estratégia urbana global. In; BIDOU-ZACHARIASEN, C. (Org.). De volta à cidade: dos processos de gentrificação às políticas de "revitalização" dos centros urbanos. São Paulo: Annablume, 2006. p. 89-120. p. 59-87.

TRINDADE JR., S-C. C. Formação metropolitana de Belém (1960-1997). Belém: Paka-Tatu, 2016. (Série Belém 400 Anos).

Produção do espaço e uso do solo urbano em Belém. Belém: NAEA, 1997.

VAN CRIEKINGEN, M. A cidade renasce! Formas, políticas e impactos da revitalização residencial em Bruxelas. In: BIDOU-ZACHARIASEN, C. (Org.). De volta à cidade: dos processos de gentrificação às políticas de "revitalização" dos centros urbanos. São Paulo: Annablume, 2006. p. 89-120.

VAZ. L. F; JACQUES, P. B. Territoires culturels de Rio. In : JEUDY, H-P ; JACQUES, P. B. Corps et décors urbains: les enjeux cultureles des villes. Paris: L'Harmattan, 2006. p. 61-78.

VENTURA NETO, R. S. Belém e o imobiliário: uma cidade entre contratos e contradições. Belém: Imprensa Oficial do Estado, 2015.

VIEIRA, B. S. Verticalização imobiliária e controle do uso e da apropriação do espaço urbano em Belém: discursos e conflitos em torno da outorga onerosa do direito de construir. 2017. 227f. Tese (Doutorado em Desenvolvimento Sustentável do Trópico Úmido) - Núcleo de Altos Estudos Amazônicos, Universidade Federal do Pará, Belém, 2017. 